\title{
El comercio de Hong Kong y su relación con México
}

DOI: 10.32870/mycp.v5i16.166

Agustina Rodríguez Alegría*

$\mathrm{E}$ e acuerdo con un estudio realizado por el Instituto Fraser de Canadá en el 2002, la economía de Hong Kong ${ }^{1}$ es considerada como la más libre del mundo. Así lo demuestra la participación de las exportaciones en el producto interno bruto (PIB), que en los años noventa mostró un elevado promedio de 140 por ciento, y que en 2000 se incrementó a $150 .^{2}$ Hong Kong es considerado así como el puerto de mayor movimiento de contenedores del mundo. En la presente colaboración se presenta un panorama general sobre el intercambio comercial y la inversión en Hong Kong con sus principales socios y la relación que guarda con México.

Tanto el comercio exterior como la inversión de Hong Kong están estrechamente relacionados con la actividad económica de China. Dos son los factores que explican la estrecha relación económica entre éstos: el crecimiento del comercio en China y la complementariedad de las dos economías, en especial la conexión entre Hong Kong y Guandong. ${ }^{3}$

A partir de que China emprendió su política de "puertas abiertas" a fines de los años setenta, su comercio exterior ha crecido a una tasa superior a la del PIB; tanto exportaciones como importaciones han mostrado un crecimiento promedio anual de 14 y 13 por ciento respectivamente. Así, su participación en las exportaciones mundiales se incrementó de 1 por ciento en 1965 a 3.4 en 1995. Aproximadamente la mitad de las exportaciones chinas ha estado compuesta por productos intensivos en el uso de mano de obra. Por otra parte, los productos intensivos en capital han aumentado su participación de 13 a 37 por ciento en el total de exportaciones chinas en el periodo 1985-1995. En este auge del comercio exterior de China, Hong Kong ha jugado un papel primordial como

* Investigadora del Departamento de Estudios del Pacífico de la Universidad de Guadalajara. intermediario: en 1996 cerca de 58 por ciento de las exportaciones chinas se hacían vía Hong Kong (16 por ciento en 1985). ${ }^{4}$ Por el lado de sus importaciones 39 por ciento se hace a través de Hong Kong.

La política china de descentralizar la administración del comercio exterior favoreció a Hong Kong, tanto por las economías de escala en la intermediación como por las economías de alcance en el uso de la información.

La complementariedad de las dos economías justifica la forma bajo la cual la actividad del comercio se lleva a la práctica; por un lado Hong Kong carece de recursos naturales y mano de obra, factores relativamente más abundantes en China. Por otro lado, el primero posee tecnología de punta y la infraestructura física y financiera que facilitan el comercio. Así, ambas economías, dados sus diferentes niveles de desarrollo, se especializan: el proceso productivo se traslada a China continental y los productos terminados son reexportados desde Hong Kong. La apertura de la economía china se ha basado en la estrategia de atracción de la inversión extranjera; entre 1979 y 1995 la inversión de Hong Kong en China representó 60 por ciento de la inversión acumulada, lo cual significó un desplazamiento masivo de las industrias intensivas en mano de obra de Hong Kong a Guangdong. La llamada Región del Delta del río Perla, en Guandong, se ha caracterizado por la internacionalización de la producción manufacturera a través de alianzas estratégicas y orientada a terceros países. La inversión hongkonesa llegó primero a establecer industrias tipo maquiladoras (sanlai yibu) para luego transformarse en industrias de inversión extranjera. Para 1996 se estimaba que había alrededor de 30 mil empresas en cada uno de esos tipos de inversión que daban empleo al menos a 3 millones de chinos. ${ }^{5}$ La reubicación de la inversión hongkonesa se debió principalmente a las diferencias en costos entre 
las dos economías. En los años sesenta y setenta, Hong Kong llevó a cabo una estrategia de industrialización orientada a las exportaciones, basada en la manufactura de productos intensivos en el uso de mano de obra. Bajo esa estrategia, la economía de Hong Kong creció a tasas muy aceleradas: para fines de los años setenta, el costo de la tierra y de la mano de obra se habían incrementado por la fuerte demanda industrial - el salario por hora en Hong Kong en 1975 fue de 0.76 US $\$$ y en 1999 de $5.44-.^{6}$ En consecuencia, las exportaciones hongkonesas fueron perdiendo competitividad y la coincidencia con la apertura china ofreció a Kong Kong una oportunidad de reubicar su industria y abaratar costos. Así, la inversión que ha llegado a Guandong lo ha convertido en la principal región exportadora de China. En 1994, las exportaciones de Guandong representaban 40 por ciento de las exportaciones de China.

No obstante desde mediados de los años noventa, China estaba tratando de reorientar la inversión extranjera hacia el sector servicios y de extenderla hacia otros centros diferentes de las áreas costeras. Adicionalmente, está implementando una política de "trato nacional" a las firmas extranjeras, lo que significa un ajuste hacia arriba en el tratamiento fiscal de que disfrutaban estas empresas, y más competencia para la Región del Delta del río Perla por parte de otras regiones de China, como la del río Yang Tse en Shanhai, y pérdida de las ventajas impositivas de que gozaba anteriormente la inversión extranjera. Este nuevo enfoque de la política de "puertas abiertas" tendrá repercusiones en el posicionamiento de la inversión hongkonesa en China.

\section{El comercio de Hong Kong}

La ubicación geográfica, el alto nivel de desarrollo y la alta competitividad de su economía, le han permitido a Hong Kong crear las condiciones propicias para abrir sus fronteras comerciales al mundo, sirviendo como puente de comercio entre éste y China. Así, aunque las exportaciones domésticas alcanzaron en el 2000 los 23 mil millones de dólares, las reexportaciones fueron 8 veces superiores $(179$ mil millones de dólares). Las exportaciones de Hong Kong están constituidas en su mayor parte por textiles y ropa (52.2 por ciento) y en segundo lugar están los productos electrónicos (20.5 por ciento) (cuadro1).

Hong Kong es el sexto mercado y fuente exportadora del mundo, antecedido solo por países como Estados Unidos, Japón, Canadá y China. El valor total de las exportaciones e

Cuadro 1

Hong Kong: Estructura de exportaciones domésticas , 1998-2001 (porcentajes con base en miles de millones HK $\$$ )

\begin{tabular}{lrrrr}
\hline & 1998 & 1999 & 2000 & 2001 \\
\hline Total & 100 & 100 & 100 & 100 \\
& & & & \\
Ropa y textiles & 45.5 & 48.9 & 47.8 & 52.2 \\
Productos electrónicos & 25.5 & 22.7 & 23.9 & 20.5 \\
Relojes & 4.7 & 2.9 & 1.7 & 1.6 \\
Joyería & 2.6 & 2.9 & 3.1 & 3.1 \\
\hline
\end{tabular}

Fuente: Ministerio de Comercio Exterior de Hong Kong, 2002

internet: http://www.info.gov.hk/hkbi/enghkbi/6/6-2a.htm. 
importaciones hongkonesas en el 2000 fue de 202.4 y 214.2 miles de millones US \$ respectivamente, resultando en un déficit de 11.8 miles de millones de US $\$ .^{7}$

En el 2001

los principales mercados para las exportaciones de Hong Kong fueron en orden de i m portancia: China, Estados Unidos, la Unión Europea, Japón y Taiwan, conservando el mismo orden en las importaciones para los países asiáticos, aunque la Unión Europea pasa a ocupar el cuarto lugar en importancia (cuadro 2).

Por su parte las reexportaciones se destinan principalmente a China y provienen de Japón y de Taiwan. Estas están compuestas de bienes de capital y materiales para producción. Dados los problemas de transporte en China, por la deficiencia en carreteras y ferrocarriles, Hong Kong es un importante intermediario que le facilita sus exportaciones
Cuadro 2

Hong Kong: principales socios comerciales, 2001

(Porcentajes con base en miles de millones HK \$) Exportaciones

Total

Reexportaciones domésticas importaciones

Total (miles de millones HK \$)

1,327

154

1,568

China

$37 \quad 32$

43

Estados Unidos

21

14

31

17

7

Japón

Taiwan

Singapur

Otros

Total

6

3

10

0

11

0

22

100

3

100

Fuente: Ministerio de Comercio Exterior de Hong Kong, 2002

internet: http://www.info.gov.hk/hkbi/enghkbi/6/6-2a.htm. de bienes que tienen como destino a Estados Unidos.

\section{El comercio de México y Hong Kong}

Hasta antes de 1998, México mantuvo un superávit comercial con Hong Kong que se fue haciendo más pequeño debido a la disminución de las exportaciones mexicanas y al incremento de las importaciones dando lugar a un creciente déficit comercial para México (gráfica 1). En el periodo 1998-2000, México exportó a Hong Kong 194 millones de dólares en promedio anual e importó 282 millones de dólares. Más de 90 por

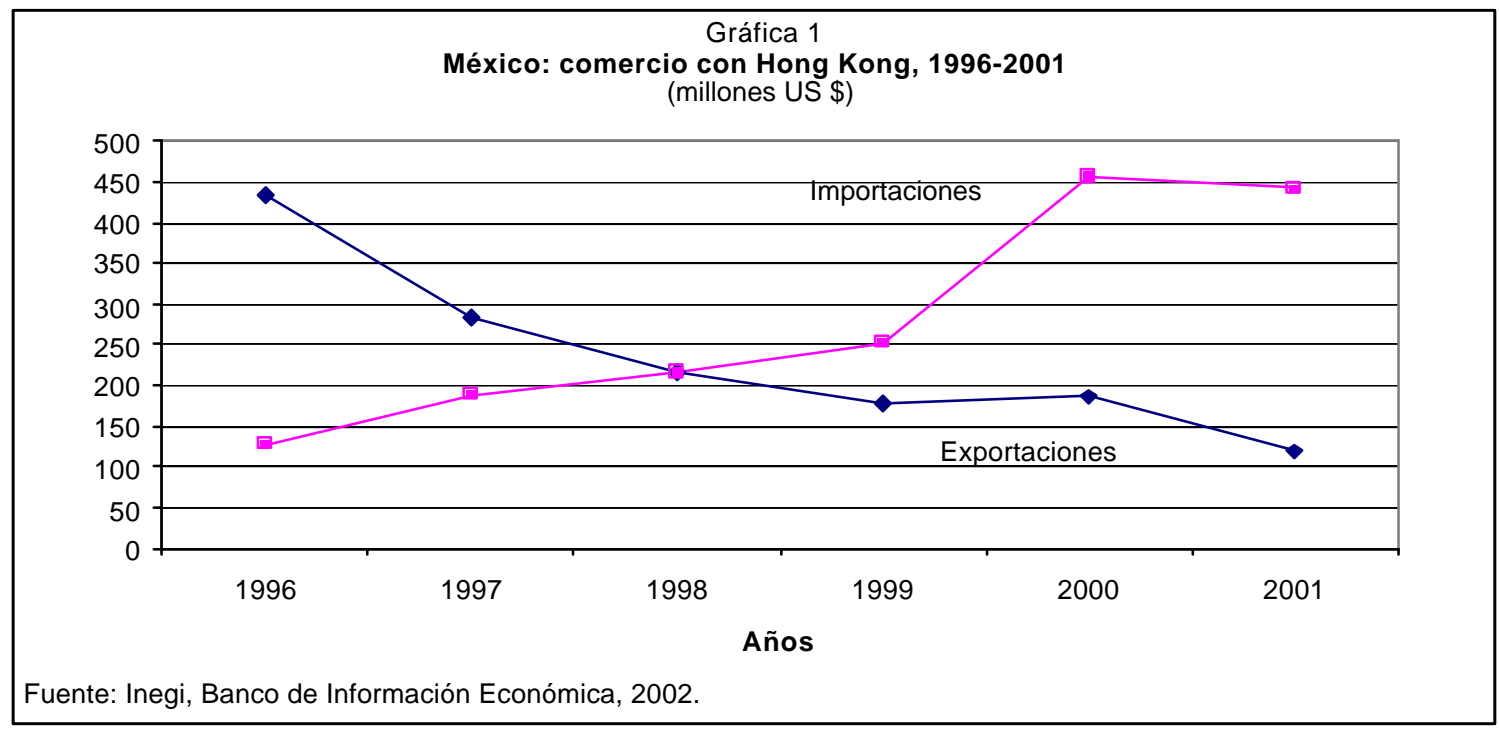


Cuadro 3

México: comercio con Hong Kong, 1998-2000

(millones U.S \$)

\begin{tabular}{|c|c|c|c|c|c|c|c|c|}
\hline & & & & & rcentaj & & Crecil & miento \\
\hline & 1998 & 1999 & 2000 & 1998 & 1999 & 2000 & $1999 / 1998$ & $2000 / 1999$ \\
\hline Exportaciones & 217.0 & 178.0 & 187.0 & 100.0 & 100.0 & 100.0 & -18.0 & 5.1 \\
\hline Subtotal & 137.4 & 142.7 & 174.4 & 63.3 & 80.2 & 93.3 & 3.9 & 22.2 \\
\hline Reactores nucleares, calderas, máquinas & & & & & & & & \\
\hline$y$ artefactos & 62.9 & 70.4 & 119.8 & 29.0 & 39.5 & 64.0 & 11.8 & 70.2 \\
\hline Materias plásticas y manufacturas & 7.5 & 5.5 & 13.2 & 3.5 & 3.1 & 7.0 & -26.9 & 139.0 \\
\hline $\begin{array}{l}\text { Máquinas, aparatos de reproduccción } \\
\text { de imagen y sonido, material eléctrico }\end{array}$ & & & & & & & & \\
\hline y sus partes & 35.0 & 46.8 & 9.6 & 16.1 & 26.3 & 5.1 & 34.0 & -79.5 \\
\hline Productos fotográficos & 8.0 & 2.2 & 7.0 & 3.7 & 1.2 & 3.7 & -72.6 & 221.1 \\
\hline Vidrios y manufacturas de vidrio & 0.8 & 1.3 & 6.0 & 0.4 & 0.7 & 3.2 & 51.7 & 375.8 \\
\hline Pescado, crustáceos y moluscos & 2.3 & 2.3 & 3.7 & 1.1 & 1.3 & 2.0 & -1.6 & 60.7 \\
\hline Pieles & 3.0 & 2.8 & 3.5 & 1.4 & 1.6 & 1.9 & -8.9 & 25.5 \\
\hline Productos químicos orgánicos & & & & & & & & \\
\hline e inorgánicos & 5.6 & 4.1 & 5.9 & 2.6 & 2.3 & 3.2 & -26.1 & 43.9 \\
\hline Fibras sintéticas o artificiales & 7.1 & 2.4 & 2.2 & 3.3 & 1.4 & 1.2 & -65.8 & -7.6 \\
\hline Algodón & 0.4 & 2.5 & 1.8 & 0.2 & 1.4 & 1.0 & 522.4 & -28.3 \\
\hline Bebidas y líquidos alcohólicos & 4.8 & 2.5 & 1.7 & 2.2 & 1.4 & 0.9 & -48.7 & -29.6 \\
\hline Otros & 79.6 & 35.3 & 12.6 & 36.7 & 19.8 & 6.7 & -55.7 & -64.3 \\
\hline Importaciones & 216.0 & 253.0 & 456.0 & 100.0 & 100.0 & 100.0 & 17.1 & 80.2 \\
\hline Subtotal & 197.3 & 227.7 & 421.0 & 91.3 & 90.0 & 92.3 & 15.4 & 84.9 \\
\hline $\begin{array}{l}\text { Máquinas, aparatos de reproduccción } \\
\text { de imagen y sonido, material eléctrico }\end{array}$ & & & & & & & & \\
\hline y sus partes & 89.9 & 88.6 & 173.6 & 41.6 & 35.0 & 38.1 & -1.5 & 96.0 \\
\hline Prendas y complementos de vestir & 38.2 & 58.9 & 143.8 & 17.7 & 23.3 & 31.5 & 54.0 & 144.2 \\
\hline Importación de mercancía mediante opera- & 161 & 151 & 188 & 75 & 60 & 41 & -62 & 240 \\
\hline Reactores nucleares, calderas, máquinas & 0.1 & & 1.0 & & & & -0.2 & 24.0 \\
\hline y artefactos & 10.2 & 13.6 & 18.1 & 4.7 & 5.4 & 4.0 & 33.2 & 33.6 \\
\hline Algodón & 10.0 & 9.4 & 17.9 & 4.6 & 3.7 & 3.9 & -5.5 & 89.7 \\
\hline $\begin{array}{l}\text { Instrumentos y aparatos de óptica, fotografía } \\
\text { o cinematrografía }\end{array}$ & 10.1 & 10.3 & 14.2 & 4.7 & 4.1 & 3.1 & 2.5 & 37.6 \\
\hline Juguetes juegos y artículos para recreo & 2.5 & 8.5 & 10.1 & 1.2 & 3.3 & 2.2 & 240.2 & 20.0 \\
\hline Relojería & 12.0 & 9.7 & 9.9 & 5.6 & 3.8 & 2.2 & -19.4 & 2.0 \\
\hline Materias plásticas y manufacturas & 4.8 & 4.5 & 5.5 & 2.2 & 1.8 & 1.2 & -5.1 & 21.2 \\
\hline Filamentos sintéticos o artificiales & 0.8 & 2.5 & 4.8 & 0.4 & 1.0 & 1.1 & 197.4 & 91.4 \\
\hline Productos editoriales & 2.6 & 6.5 & 4.2 & 1.2 & 2.6 & 0.9 & 152.0 & -35.5 \\
\hline Otros & 18.7 & 25.3 & 35.0 & 8.7 & 10.0 & 7.7 & 35.1 & 38.2 \\
\hline
\end{tabular}

Fuente: Bancomext, World Trade Atlas, 2000.

ciento de las exportaciones mexicanas a Hong Kong están concentradas en reactores nucleares, calderas máquinas y artefactos. Las importaciones por su parte están constituidas por dos grupos de bienes: por un lado, máquinas y aparatos de reproducción de imagen y sonido y material eléctrico (38.1 por ciento), y por el otro, prendas y complementos de vestir (31.5 por ciento) (cuadro 3).

\section{Inversión en Hong Kong}

Tanto por su posición geográfica estratégica como por el elevado desarrollo de su 
infraestructura física y financiera y las condiciones favorables de la inversión, Hong Kong es una de las economías más atractivas a la inversión exterior.

El stock de IED en Hong Kong, en 2000, ascendió a 3,551.3 miles de millones de dólares en valor de mercado, 12.7 por ciento superior que en 1999. China fue la más importante fuente de IED, con una participación de 31.3 por ciento de la IED acumulada al 2000. Para 1979 había únicamente 122 compañías chinas en Hong Kong. Una década después ese número se había incrementado a más de 2000 compañías. Estas empresas tienen una importante penetración en diferentes sectores de la economía hongkonesa: tanto en las reexportaciones como en los servicios de turismo a China, las empresas de China continental participan con 50 por ciento del mercado; en el sector de bienes raíces con 33 por ciento; en transporte de carga y comercio 25 por ciento al igual que en depósitos bancarios. Por otro lado, Hong Kong se ha convertido en un centro vital financiero para levantar fondos del exterior para empresas chinas, a través de la bolsa hongkonesa.

Otros países inversores en Hong Kong son Holanda y Estados Unidos, con 6.3 y 4.5 por ciento en el total respectivamente.

\section{Inversión de Hong Kong en México}

Hasta diciembre de 2001 México contaba con 30 empresas originarias de Hong Kong, lo que representa 0.1 por ciento del total de sociedades con IED establecidas en México $(23,110)$. Entre las empresas hongkonesas más representativas, cuatro se dedican a prestar servicios, tres a la confección de prendas de vestir, otras tres a comercio de productos no alimenticios al por mayor, dos al comercio de alimentos, bebidas y tabaco al por mayor y dos a servicios inmobiliarios.

En el periodo de 1994-2001, la IED procedente de Hong Kong alcanzó un monto de 23.1 millones de dólares, equivalente a 0.5 por ciento de la inversión proveniente de los países de la Cuenca del Pacífico (4,226.1 millones de dólares). Hong Kong ocupa así el séptimo lugar, después de Japón (3,173.7 millones de dólares), Corea del Sur (541.1 millones de dólares), Singapur (295.9 millones de dólares), Taiwan (74.8 millones de dólares), Australia (55.3 millones de dólares) y China (40.7 millones de dólares). ${ }^{8}$

La IED originaria de Hong Kong en México alcanzó su nivel más alto en 1996 con 6.6 millones de dólares. Sin embargo, en 1997 disminuyó a 0.47 millones de dólares, lo que se explica por las condiciones que enfrentaba Hong Kong cuando, por un lado, se vio afectado por su integración a la República Popular China y, por el otro, debido al impacto que sufrió por la crisis asiática. Aunque en años posteriores se recuperó la inversión, el monto acumulado anual sigue siendo inferior a 1997.

La IED proveniente de Hong Kong se destina principalmente a la industria manufacturera, en la que se ubica 94.1 por ciento de la inversión; 70 por ciento de ésta está concentrada en la industria textil y 30 por ciento restante en el ensamble de productos electrónicos y automóviles (cuadro 4).

\section{Comentarios finales}

La apertura de la economía de Hong Kong no tiene precedente. Su política comercial ha sido orientada a la liberalización, y actualmente no tiene ninguna legislación sobre medidas antidumping, derechos compensatorios $\mathrm{y}$ salvaguardas. ${ }^{9}$ Hoy, que ya es una economía desarrollada, su estrategia es crear la infraestructura necesaria para penetrar en esferas que requieren innovación y especialización, con la finalidad de promover la competencia global, transparente y amplia. La flexibilidad que ha mostrado al irse adaptando a las nuevas situaciones de competencia y de ir aprovechando las oportunidades que se le han presentado, son un modelo de relevancia para México, sobre todo ahora que la competencia china está afectando a algunos sectores de la economía mexicana. Por otra parte, ahora que las condiciones de la política de apertura de 


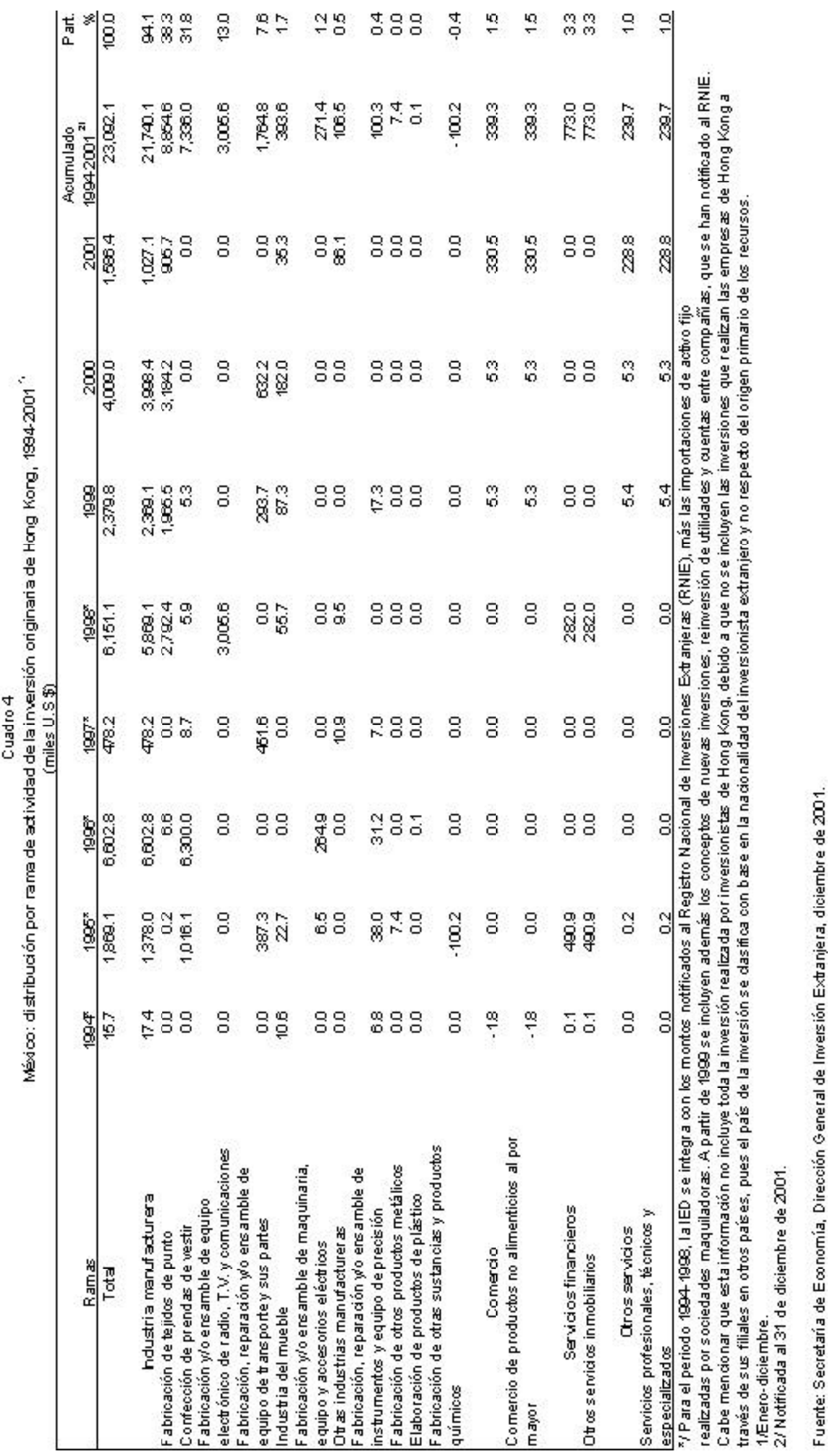


China están cambiando, la IED hongkonesa al exterior buscará otras oportunidades, y México, con los tratados de libre comercio que tiene con 32 economías, ofrece un atractivo a la inversión, dada su posición estratégica.

Las ventajas comparativas son dinámicas y se modifican a medida que un país avanza en su desarrollo. La estrategia debe hacer énfasis en la flexibilidad de adaptación y en el aprovechamiento de nuevas oportunidades.

\section{Notas}

1 A partir de 1997, Hong Kong pasó a ser parte de China; sin embargo, mantiene autonomía en su política de comercio, incluyendo un sistema de tarifas independiente y de cuotas de exportación; bajo el nombre de "Hong Kong China" podrá negociar separadamente con países y regiones; la inversión hongkonesa en China será tratada como inversión extranjera y Hong Kong utilizará su propia moneda y una política monetaria independiente. Cheng, Yukshing, Lu, Weigyo, Findlay, Christopher, "Hong Kong's Economic Relationship with China" en Journal of the Asia Pacific Economy, vol. 3, núm. 1, 1998, p. 104.

2 Fondo Monetario Internacional, Estadísticas Financieras, enero de 2002, p. 240.

3 Para un análisis detallado de las razones de la intensidad del comercio entre China y Hong Kong véase, Cheng, Yuk-shing, Lu, Weigyo y Findlay, Christopher, "Hong Kong's Economic Relationship with China".

4 Op. cit., Cheng, et al., p. 111.

5 Ibid., p. 117.

6 US Department of Labor, Bureau Labor Statistics, Foreign Labor Statistics, http:// stats.bls.gov/ flshome.htm.

7 Organización Mundial del Comercio, Estadísticas de Comercio Internacional, 2001, p. 24.

8 Secretaría de Economía, Dirección General de Inversión Extranjera, diciembre 2001, pp. 2-3.

9 El Colegio de México, Centro de Estudios de Asia y África, Programa de Estudios APEC, Asia Pacífico, 2000, p. 272 . 